\title{
The effectiveness of educational programmes in ventilator bundle implementation: a systematic review
}

\author{
M Jansson ${ }^{1 *}$, H Kyngäs², M Kääriäinen ${ }^{3}$
}

\section{Abstract \\ Introduction}

Ventilator-associated pneumonia (VAP) is the most frequent nosocomial infection encountered in critical care settings. Thus, several packages (ventilator bundles, VBs) have been designed to help reduce or eliminate VAP, promote adherence to evidence-based guidelines and thus improve clinical outcomes. The aim of this systematic review was to assess current literature regarding the effectiveness of educational programmes on their implementation.

Materials and methods

A comprehensive literature search strategy was formulated in association with an information specialist. We then reviewed studies published between 2003 and 2012 listed in seven multidisciplinary databases (Ovid MEDLINE ${ }^{\circledR}$, the Cumulative Index to Nursing and Allied Health Literature, Cochrane Library, Scopus, Web of Science, Medic and Academic Search Premier). The study selection and quality assessment were carried out by two researchers independently and objectively.

Results

Six original studies were included in the final review. Educational programmes were linked to significant improvements in the overall

\footnotetext{
*Corresponding author

Email:miiajans@mail.student.oulu.fi

${ }^{1}$ Division of Intensive Care,Department of Anesthesiology, Oulu University Hospital, Oulu, Finland; Institute of Health Science, University of Oulu, Finland

${ }^{2}$ Institute of Health Science,University of Oulu, Finland; Research Consultant, Oulu University Hospital, Oulu, Finland

${ }^{3}$ Institute of Health Science, University of Oulu, Oulu, Finland
}

adherence to VBs and a significant decrease in adverse clinical outcomes such as the incidence of VAP, monthly use of sedatives, duration of mechanical ventilation and hospitalisation costs.

\section{Conclusion}

Education programmes about VBs can promote adherence to evidencebased guidelines and thus reduce the incidence of VAP. However, they are often inconsistently developed, implemented and evaluated. There are needs for both effective educational programmes and a universal method for evaluating their outcome.

\section{Introduction}

Ventilator-associated pneumonia (VAP) is the most frequent deviceassociated, nosocomial infection in critical care settings ${ }^{1-3}$, causing substantial morbidity, a two-fold increase in mortality rates ${ }^{4}$, excess $\operatorname{costs}^{5}$ and prolonged use of ventilators ${ }^{4}$, intensive care unit stays and hospital stays ${ }^{4,6}$.

According to previous literature, healthcare staff's adherence ${ }^{7-10}$ to infection control procedures is currently insufficient due to the lack of time ${ }^{11,12}$, inaccessible supplies and a lack of knowledge ${ }^{11-15}$, which may jeopardise patient safety, and thus the quality of care ${ }^{16}$.

The Institute for Healthcare Improvement ${ }^{17}$, the Centres for Disease Control and Prevention ${ }^{18}$ and Rello et al. ${ }^{19}$ have designed several 'packages' of evidence-based guidelines (EBGs), known as 'VAP bundles' (ventilator bundles, VBs), to promote adherence to EBGs, thereby reducing or eliminating VAP and improving clinical outcomes. The evidencebased interventions include combinations of sedation vacation and use of weaning protocols ${ }^{17,19}$, elevation of the head of the bed between $30^{\circ}$ and $45^{\circ 17,18}$, daily oral care with chlorhexidine $^{17-19}$, adequate hand hygiene ${ }^{17-19}$, and ulcer and deep vein thrombosis prophylaxis ${ }^{17}$.

The initiation of VBs is an effective method for VAP reduction when adherence is maintained ${ }^{20-22}$. VB training can promote adherence to EBGs and thus reduce the incidence of VAP. However, it is often inconsistently developed, implemented and evaluated $^{4}$. The aim of the present study was to assess the current body of literature regarding the effectiveness of educational programmes on the implementation of VBs, in order to identify ways to intensify current development-evaluation-implementation practices.

\section{Materials and methods \\ Search strategy}

A systematic review was conducted in the autumn of 2012 in accordance with the guidelines of the Centre for Reviews and Dissemination ${ }^{23}$ and the Joanna Briggs Institute ${ }^{24}$. A limited review of Medic, Ovid MEDLINE ${ }^{\circledR}$ and the Cumulative Index to Nursing and Allied Health Literature (CINAHL), was initially conducted to identify optimal search terms ${ }^{24}$.

The final review focused on peerreviewed empirical studies written in English, Swedish or Finnish (due to a lack of resources and facilities for translation of other languages) and was published during the past 10 years (2003-2012). The review (Table 1) covered seven multidisciplinary databases (Ovid Medline ${ }^{\circledR}$, CINAHL, Cochrane Library, Scopus, Web of Science, Medic and Academic Search Premier). A comprehensive literature search strategy was formu- 


\begin{tabular}{|l|l|}
\hline \multicolumn{2}{c}{ Table 1. Databases and number of original studies. } \\
\hline \multicolumn{1}{|c|}{ Database } & \multicolumn{1}{c|}{ Number of original studies } \\
\hline Ovid Medline $^{\circledR}$ & 54 \\
\hline CINAHL* $^{*}$ & 40 \\
\hline Cochrane Library & 1 \\
\hline Scopus & 93 \\
\hline Web of Science & 68 \\
\hline Medic & 0 \\
\hline Academic Search Premier & 54 \\
\hline
\end{tabular}

*CINAHL, Cumulative Index to Nursing and Allied Health Literature.

\section{Table 2. Review questions and inclusion criteria .}

\section{Review questions}

Population

Intervention

Adverse outcomes

Study design

RCT, randomised controlled trial; VAP, ventilator-associated pneumonia.

lated in association with a library information specialist, based on comparison of outputs of advanced and basic searches with appropriate permutations of terms ${ }^{23,24}$. The search terms were as follows: 'ventilatorassociated pneumonia', 'pneumonia ventilator associated', or 'VAP' and educate* or teach* ${ }^{*}$ denotes that the used search terms were shortened to obtain more studies in which these terms had been used).

Inclusion criteria and study selection The study selection process was carried out by two researchers independently and objectively ${ }^{23,24}$. Studies were included if they met the inclusion criteria (Table 2) based on the research questions, populations (registered critical nurses or

\section{Inclusion criteria}

Critical care, critical care unit Intensive care, intensive care unit Adults

Education: continuing education, ongoing education, clinical education, inter-professional education

Incidence of VAP, mortality, morbidity, adverse events, length of stay, complications, errors, readmission, admission

$\mathrm{RCT}$, case control and intervention studies published between 2003-2012 in English, Swedish or Finnish

intensive care nurses), intervention (educational intervention used with or without other educational strategies in implementing VBs), type of the outcome (clinical outcome) and the study design (intervention studies). Reviews and studies that did not meet the inclusion criteria or did not include VBs were excluded.

Studies were selected in three stages (Figure 1) to minimise the risk of errors and bias and to ensure that all relevant studies were included. The study selection process was carefully documented to ensure reproducibility using RefWorks ${ }^{\circledR}$, a webbased research management tool ${ }^{23,24}$.

In the firststage $(n=310)$, duplicate publications $(n=130)$ in the seven databases were excluded from the review to reduce publication bias ${ }^{23,24}$. In the second stage, potentially relevant studies were assessed by two reviewers independently by comparing the titles $(n=180)$ and abstracts $(n=40)$ against the predetermined inclusion criteria ${ }^{23,24}$. In the third stage, the full texts $(n=7)$ of studies that appeared to meet the inclusion criteria were obtained for detailed assessment against the inclusion criteria ${ }^{23,24}$. There was complete agreement between the reviewers' final selections.

\section{Quality assessment}

The widely used, standardised, Critical Appraisal Checklist for Cohort/ Case Control Appraisal ${ }^{25}$ was used to assess the quality of the relevant studies $(n=7)$ prior to their inclusion in the final review. The quality of the studies was assessed by two reviewers independently, a content expert and a methodological expert ${ }^{23,24}$, using a scoring system in which one point was awarded for the inclusion of each relevant criterion (quality score range, $0-9$ ). Studies, with $\geq 5$ points were included in the final review.

\section{Data extraction and analysis}

The extracted data included specific details about the study designs, settings and participants, and interventions and results, which were extracted by both primary and secondary reviewers and crosschecked (Table 3). A p-value of less than 0.05 was considered statistically significant. Further analysis was limited because of the lack of available data. One study was excluded due to poor quality.

\section{Results}

Six out of the seven original studies $(85.7 \%)$ were included in the final review (Figure 1). The quality of each included study was assessed as high ( $\geq 50 \%$ of maximum possible score).

\section{Study characteristics}

Most (66.7\%) published studies were single-centre studies, conducted in Canada $^{26}$, Germany ${ }^{27}$ and the $\mathrm{UK}^{28,29}$. The most commonly used (100\%)

\section{Licensee OA Publishing London 2013. Creative Commons Attribution Licence (CC-BY)}




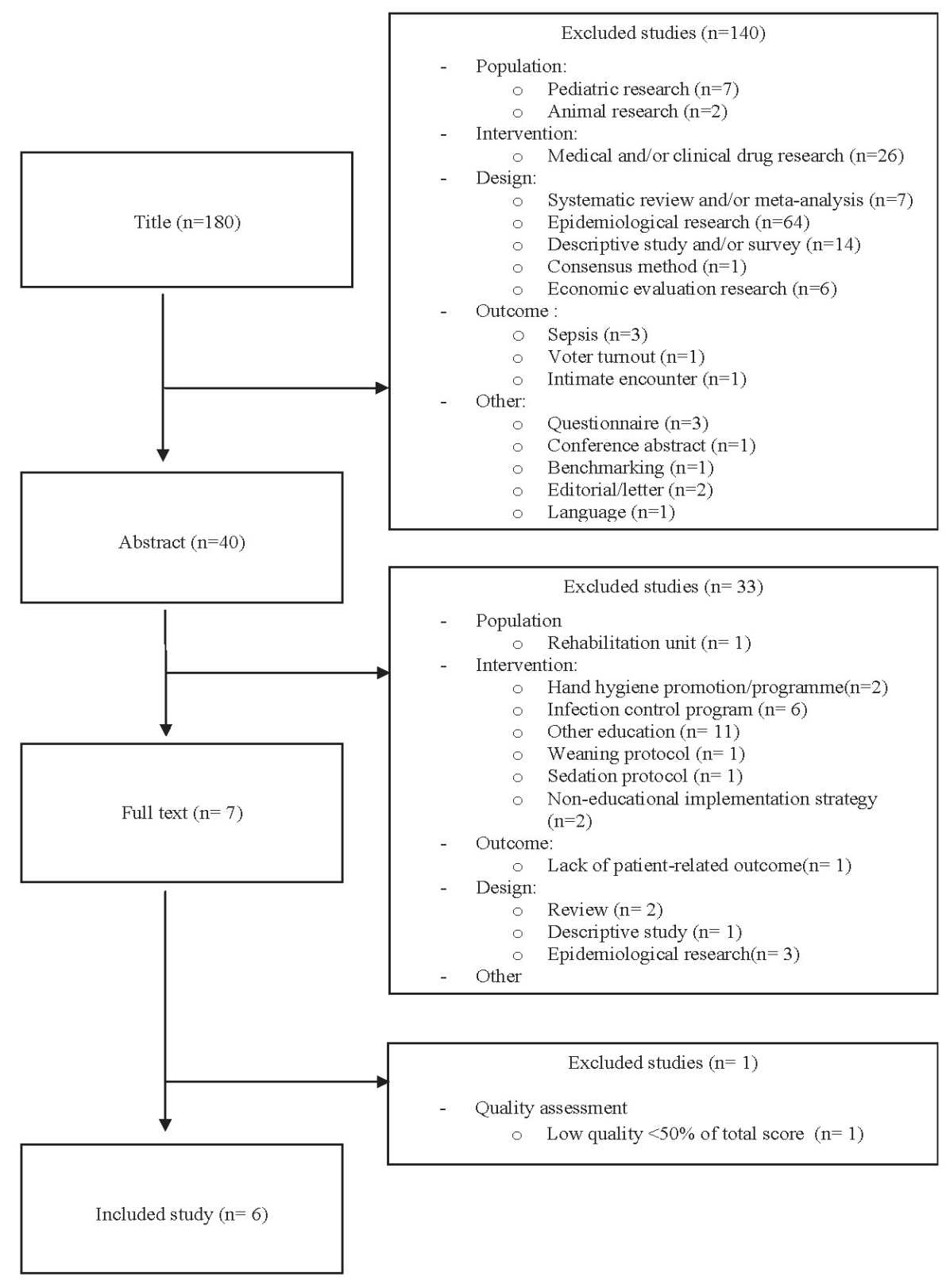

Figure 1: Flow-chart of the study selection process.

research design was a prospective, observational intervention study including pre- and post-measurements (Table 3). The other included studies were quasi-experimental observational intervention studies, comparing pre- and post-intervention outcomes from different units in a single hospital or between multiple hospitals ${ }^{30,31}$.

\section{Ventilator bundles}

The VBs considered in the examined studies consisted of modified
Institute for Healthcare Improvement bundles ${ }^{27,29}$ and other protocols including three to five evidence-based interventions that have been shown to improve clinical outcomes ${ }^{26,28,30,31}$. These include combinations of sedation vacation and use of weaning protocols $^{28,29,31}$, elevation of the head of the bed ${ }^{26,27,29,30}$, daily oral care with chlorhexidine ${ }^{28-30}$, ulcer ${ }^{26,27,31}$ and/or deep vein thrombosis prophylaxis ${ }^{27,31}$, adequate hand hygiene ${ }^{26,30}$ and glove use $^{30}$, nutrition ${ }^{26}$, lung protective ventilation $^{27}$ and management of ventilator tubing condensate ${ }^{26,28,30}$.

\section{Educational interventions}

Educational programmes addressed in the studies consisted of selfstudy modules ${ }^{30}$, repeated lectures ${ }^{27}$, workshops $^{28}$ and several brief $^{26}$ or standardised sessions ${ }^{29}$. All the included intervention studies considered other complementary interventions: teaching materials ${ }^{28-30}$, multidisciplinary education meetings ${ }^{28,30}$, storyboards ${ }^{30}$ and reminders, such as e-mails ${ }^{30}$, posters ${ }^{26,29}$ or other visual aids ${ }^{26-29}$. Moreover, training was supplemented with feedback ${ }^{27-30}$, VAP rate reports ${ }^{30,31}$ and reinforcement at the bedside ${ }^{28}$. In addition, DePalo et al. ${ }^{31}$ identified hazards, learned from defects and implemented teamwork tools (Table 3 ).

Critical care nurses' adherence to VBs Fifty percent of the included studies found that educational interventions increased overall VB adherence significantly ${ }^{27,28,31}$ and the others found that the interventions extremely significantly ( $p=0.000$ ) increased observed hand hygiene practices and glove use (Table 3$)^{30}$. Two or three studies found that they significantly increased adherence to elevation of the head of the bed ${ }^{27-29}$, daily oral care with chlorhexidine ${ }^{28,29}$ and documented adherence to weaning protocols ${ }^{28,29}$. In addition, Bloos et al. ${ }^{27}$ reported that they significantly increased the use of ulcer and deep vein thrombosis prophylaxis ( $p=0.048$ ), but Omrane et $a{ }^{26}$ detected no significant change in adherence to prophylaxis.

\section{Clinical outcomes}

Following educational interventions, $66.7 \%$ of the included studies found that the incidence of VAP decreased significantly ${ }^{26,28,29,31}$ and one study ${ }^{31}$ reported that the long-term effects were maintained over 48 months of follow-up (Table 3). In addition, Morris et al. found that rates of methicillin-resistant Staphylococcus aureus acquisitions decreased significantly $(p<0.001)^{29}$. 
Table 3. The study characteristics of included original studies with quality scores $\geq 50 \%(n=6)$.

\begin{tabular}{|c|c|c|c|}
\hline Study & Sample and settings & Design & Interventions \\
\hline $\begin{array}{l}\text { Abbot } \\
\text { et al. } \\
2006\end{array}$ & $\begin{array}{l}\text { Conducted in five } \\
\text { ICUs in two medi- } \\
\text { cal centres among } \\
\text { all hospital staff and } \\
\text { adult mechanically } \\
\text { ventilated patients } \\
\text { ( } n=106) \text { admitted to } \\
\text { the ICUs before and } \\
\text { after intervention in } \\
\text { the USA }\end{array}$ & $\begin{array}{l}\text { Prospective, } \\
\text { observational, } \\
\text { quasi-experi- } \\
\text { mental design } \\
\text { with pre- (from } \\
\text { April, May and } \\
\text { June 2002) and } \\
\text { post-intervention } \\
\text { (from April, May } \\
\text { and June 2004) } \\
\text { measurements }\end{array}$ & $\begin{array}{l}\text { Ventilator bundle: elevation of the } \\
\text { head of the bed, oral care, condensate } \\
\text { removal, hand hygiene, glove use } \\
\text { Educational interventions: self-learn- } \\
\text { ing packets, educational materials, } \\
\text { and storyboards, one-on-one teach- } \\
\text { ing with clinicians } \\
\text { Reminders: E-mails } \\
\text { Feedback: VAP* rate reports, feed- } \\
\text { back on guideline adoption }\end{array}$ \\
\hline $\begin{array}{l}\text { Bloos et } \\
\text { al. } 2009\end{array}$ & $\begin{array}{l}\text { Conducted in an ICU } \\
\text { in a tertiary care } \\
\text { university hospital } \\
\text { among hospital and } \\
\text { post-surgical staff } \\
\text { in charge and all } \\
\text { adult mechanically } \\
\text { ventilated patients } \\
\text { admitted to the ICU } \\
\text { before ( } n=133 \text { ) } \\
\text { and after ( } n=141 \text { ) } \\
\text { intervention in } \\
\text { Germany }\end{array}$ & $\begin{array}{l}\text { A prospective, } \\
\text { cohort study } \\
\text { with pre- (from } \\
\text { June to Septem- } \\
\text { ber 2005) and } \\
\text { post- interven- } \\
\text { tion (from March } \\
\text { to June } 2006 \text { ) } \\
\text { measurements }\end{array}$ & $\begin{array}{l}\text { Modified IHI bundle: elevation of } \\
\text { the head of the bed, lung protec- } \\
\text { tive ventilation, ulcer and deep vein } \\
\text { thrombosis prophylaxis } \\
\text { Educational interventions: daily } \\
\text { seminars (the scientific background } \\
\text { and technique of the bundle) for a } \\
\text { two-month period } \\
\text { Reminders: red marks were attached } \\
\text { on the walls to indicate a correct } \\
\text { semi recumbent position } \\
\text { Feedback: monitoring daily adher- } \\
\text { ence to the treatment bundles and } \\
\text { individually trained nurses and resi- } \\
\text { dents if the bundle was not correctly } \\
\text { applied for a two-month period }\end{array}$ \\
\hline
\end{tabular}

Results

No statistically significant reduction in the overall VAP* rates in a two-year follow-up ICU length of stay declined resulting in costs savings of approximately \$23000-40000

Observed hand hygiene practices improved $(p=0.000)$

Observed use of gloves increased $(p=0.000)$

Overall bundle adherence increased from $15 \%$ to $33.8 \%$ $(p<0.001)$

Elevation of the head of the bed was achieved in 24.9\% of patient days before and $46.9 \%$ of patient days after $(p<0.001)$

Admission of deep vein thrombosis prophylaxis increased from 89.5 to $91.5 \%$ $(p=0.048)$

Ulcer prophylaxis was achieved in both groups

Median tidal volume remained unaltered

Days of mechanical ventilation reduced from 6 to 4 days $(p=0.017)$

ICU length of stay, ICU mortality and rate of VAP** remained unaffected In patients with VAP, the median ICU length of stay was reduced by 9 days $(p=0.04)$

Significantly less patients received propofol $(p=0.01)$ 


\begin{tabular}{|l|l|}
\hline \multicolumn{1}{|c|}{ Study } & Sample and settings \\
\hline $\begin{array}{l}\text { DePalo } \\
\text { et al. }\end{array}$ & $\begin{array}{l}\text { Conducted in } 23 \\
\text { ICUs in } 11 \text { hospitals } \\
\text { among ICU staff and } \\
\text { all adult ICU patients } \\
\text { admitted to the ICUs } \\
\text { before and after } \\
\text { intervention in the } \\
\text { USA }\end{array}$ \\
\end{tabular}

\section{Hawe et Conducted in a}

al. 2009 medical-surgical ICU among ICU staff and all adult mechanically ventilated patients ( $n=1068$ ) admitted to the ICU before ( $n=675)$ and after $(n=393)$ intervention in the UK

$\quad$ Design
A prospective,
cohort study
design with pre-
(from January
to March 2006)
and post-inter-
vention (from
January 2006
to June 2008)
measurements

Quasi-experimental study with pre- (from 1 September 2005 to 27 September 2007) and post-intervention (from 27 September 2007 to 31 September 2007) measurements

\begin{tabular}{l|l} 
Morris & Conducted in mixed \\
et al. & medical-surgical ICU \\
2011 & in a teaching hospi- \\
& tal among all adult \\
& patients admitted \\
& to the ICU for $48 \mathrm{~h}$ \\
& or more during the \\
periods before \\
( $n=1460)$ and \\
after ( $n=501)$ \\
intervention in the \\
UK
\end{tabular}

A before-after Modified IHI bundle: elevation of the intervention study

VAP surveillance*** data from January 2005 to February 2008 were used as baseline data, from September 2008 to August 2009 as the 'postVAP prevention bundle implementation' period

Modified IHI bundle: elevation of the
head of the bed, oral chlorhexidine implementation

Educational interventions: nurse and medical champions, education sessions, teaching materials

Reminders: changing the 24-h observation charts, bedside cues Feedback: feedback on adherence at meetings by e-mails and posters

Interventions
Ventilator bundle: daily assess-
ment for liberation from mechanical
ventilation, elevation of the head
of the bed, following commands as
an indication of appropriate seda-
tion, ulcer and deep vein thrombosis
prophylaxis
Educational interventions: educating
staff on the science of safety, identify-
ing hazards, identifying senior execu-
tive partners, learning from defects
and implementing teamwork tools
Feedback: VAP* rate reports

Ventilator bundle: elevation of the head of the bed, oral antisepsis with chlorhexidine, use of sub-glottic suction/drainage endotracheal tubes, daily sedation breaks, daily assessment of readiness to wean and 'tubing management'

Educational interventions: workshops (definition, epidemiology, pathogenesis, risk factors, consequences of VAP), written material, multidisciplinary education meetings; barriers affecting delivery of care were identified and iteratively improved

Reminders: laminated copies of the bundle, charts

Feedback: feedback of process measurement and feedback of outcome measurement

Other: organisational change, multidisciplinary morning rounds gel, sedation holds, weaning protocol
Adherence to all VB elements increased significantly after active implementation $(p<0.0001)$

VAP*** rates reduced from 19.2 to 7.5 per 1000 ventilator days

There was a trend towards a lower unit mortality $(p=0.06)$

Adherence to elevation of the head of the bed and the use of oral chlorhexidine gel were 95\%-100\%

Documented adherence to 'wake and wean' elements was $70 \%$

Overall bundle adherence to VB was $70 \%$

Incidence of VAP*** reduced from 32 to 12 days per 1000 ventilator days $(p<0.001)$

Rates of MRSA decreased from $10 \%$ to $3.6 \%$ ( $p<0.001$ 


\begin{tabular}{|c|c|c|c|c|}
\hline Study & Sample and settings & Design & Interventions & Results \\
\hline $\begin{array}{l}\text { Omrane } \\
\text { et al. } \\
2007\end{array}$ & $\begin{array}{l}\text { Conducted in an ICU } \\
\text { in a tertiary care } \\
\text { teaching hospital } \\
\text { among ICU staff and } \\
\text { all adult mechanically } \\
\text { ventilated patients } \\
\text { admitted to the ICU } \\
\text { before ( } n=349 \text { ) and } \\
\text { after ( } n=360 \text { ) inter- } \\
\text { vention in Canada }\end{array}$ & $\begin{array}{l}\text { Pre- (from } \\
\text { November } 2003 \\
\text { to May 2004) and } \\
\text { post-intervention } \\
\text { (from November } \\
2004 \text { to May } \\
2005 \text { ) observa- } \\
\text { tional study }\end{array}$ & $\begin{array}{l}\text { Ventilator bundle: nutrition, hand } \\
\text { hygiene, patient positioning, ulcer } \\
\text { prophylaxis, the ventilator circuits } \\
\text { Educational interventions: } 12 \text { educa- } \\
\text { tion sessions (regarding aetiology, } \\
\text { morbidity and mortality of VAP, } \\
\text { prevention protocol) } \\
\text { Reminders: in service programmes } \\
\text { during the study period, posters; a } \\
\text { plastified copy of the protocol was } \\
\text { incorporated into every patient medi- } \\
\text { cation Kardex }\end{array}$ & $\begin{array}{l}\text { Hospital length of stay re- } \\
\text { mained unaffected ( } p=0.35 \text { ) } \\
\text { Total duration of mechani- } \\
\text { cal ventilation remained } \\
\text { unaffected ( } p=0.2 \text { ) } \\
\text { Antibiotic treatment duration } \\
\text { remained unaffected } \\
\text { ( } p=0.23 \text { ) } \\
\text { Use of stress ulcer prophy- } \\
\text { laxis remained unaffected } \\
\text { ( } p=0.08 \text { ) } \\
\text { Early-onset VAP* decreased } \\
\text { from } 31 \text { to } 18.5 \text { per } 1000 \\
\text { ventilator-days ( } p<0.001 \text { ) } \\
\text { Incidence of late-onset VAP* } \\
\text { increased from } 21.9 \text { to } 24.15 \\
\text { per } 1000 \text { ventilator days } \\
\text { ( } p<0.001 \text { ) }\end{array}$ \\
\hline
\end{tabular}

* The definition of VAP was derived from the National Nosocomial Infections Surveillance system, ** The definition of VAP was derived from the Clinical Pulmonary Infection Score, *** The definition of VAP was derived from the Hospitals in Europe Links for Infection Control Surveillance.

ICU, intensive care unit; IHI, Institute for Healthcare Improvement; MRSA, methicillin-resistant Staphylococcus aureus; VAP, ventilator-associated pneumonia; VB, ventilator bundle.

Increased adherence to VBs did not affect the mean duration of hospital stay $^{26,27}$. However, Bloos et al. ${ }^{27}$ found that it significantly decreased the median length of stay of patients with VAP ( $p=0.04$ ). These authors also reported that it significantly $(p=0.017)$ reduced the total duration or median tidal volume of mechanical ventilation, but not Omrane et al. ${ }^{26}$, who found no change in this variable. Bloos et al. ${ }^{27}$ and Abbot et al. ${ }^{30}$, respectively, found that it significantly reduced the monthly use of sedatives and hospitalisation costs (Table 3). However, the monthly use of antibiotics remained unaffected ${ }^{26,29}$. Two of the studies detected a trend towards lower mortality associated with adherence to $\mathrm{VBs}^{28,29}$.

\section{Discussion}

A comprehensive literature search strategy was formulated, studies were selected and their quality was assessed in accordance with the guidelines of the Centre for Reviews and Dissemination ${ }^{23}$ and Joanna Briggs Institute ${ }^{24}$. According to our findings, active implementation strategies (i.e. educational programmes) were linked to significant improvements in the overall adherence to VBs and a significant decrease in clinical outcomes: incidence of VAP, monthly use of sedatives, duration of mechanical ventilation and hospitalisation costs.

VBs are an important component of patient safety. Implementation of a VB can support and improve the quality and delivery of care of mechanically ventilated patients in critical care settings. However, the average adherence to VBs in the baseline measurements was insufficient, which is in line with previous studies $^{4,7-10}$. Overall, the use of active implementation strategies led to a significant increase in adherence to VBs in $50 \%$ of included studies ${ }^{27,28,31}$.
However, according to Klompas ${ }^{4}$, the adherence to VB components must be $>95 \%$ to realise the bundle's full potential.

A significant reduction in the incidence of VAP following educational programmes was observed in most of the included studies ${ }^{26,28,29,31}$, but Abbot et al..$^{30}$ and Bloos et al. ${ }^{27}$ found no statistically significant reduction in the overall VAP rates. The variability of results in the included studies might be due to the wide range of definitions of VAP applied and the lack of a universal method of outcome evaluation ${ }^{4}$. The definitions of VAP were derived from the National Nosocomial Infections Surveillance ${ }^{30}$, the Clinical Pulmonary Infection Score ${ }^{26,27,31}$ and Hospitals in Europe Links for Infection Control Surveillance ${ }^{28,29}$ systems. The lack of a universal method of outcome evaluation (i.e. variations in the research 
designs, lack of standardised instruments, measurements and follow-up times) raises questions about the validity of estimated effects and limits generalisability ${ }^{32,33}$.

Variations in the implementation strategies (i.e. in the execution and frequency of education), VBs (various complementary interventions, e.g. reminders, feedback etc.) and endpoints, make intrahospital comparisons and trend determinations difficult or even impossible. In addition, the development-evaluation-implementation processes addressed in the included studies were often inadequately reported. Moreover, the effects of extraneous factors or other potential sources of bias $^{25}$ on their findings were inadequately reported resulting in both practical and methodological difficulties in the evaluation of their findings.

The search strategy focused only on peer-reviewed empirical studies written in English, Swedish or Finnish and published during the past 10 years (2003-2012), which may have led to publication or language bias $^{23,24}$. However, the results clearly show that further research is needed to design multi-centre, parallel or cluster randomised controlled, follow-up trials. The development of a universal method of outcome evaluation and a more objective surveillance definition for VAP is required to facilitate further evaluation of the relationship between educational implementation strategies and clinical outcomes. Regular auditing and active implementation strategies (i.e. adequate support) for critical care nurses are required to assess and improve their professional capabilities and current practice.

\section{Conclusion}

Educational programmes about VBs can promote adherence to evidencebased guidelines and thus reduce the incidence of VAP. However, they are often inconsistently developed, implemented and evaluated. There are needs for both effec- tive educational programmes and a universal method for evaluating their outcome.

\section{Abbreviations list}

CINAHL, Cumulative Index to Nursing and Allied Health Literature; EBGs, evidence-based guidelines; VAP, ventilator-associated pneumonia; $\mathrm{VB}$, ventilator bundles.

\section{Acknowledgements}

The authors acknowledge the assistance of the information specialist Sirpa Grekula, Oulu University Medical Library, Oulu, Finland.

\section{References}

1. Safdar N, Dazfulian C, Collard HR, Saint S. Clinical and economic consequences of ventilator-associated pneumonia: a systematic review. Crit Care Med. 2005 Oct;33(10):2184-93.

2. Bouza E, Hortal J, Muñoz P, Pascau J, Pérez MJ, Hiesmayr M. European Study Group on Nosocomial Infections; European Workgroup of Cardiothoracic Intensivists. Postoperative infections after major heart surgery and prevention of ventilator-associated pneumonia: a one-day European prevalence study (ESGNI-008). J Hosp Infect. 2006 Nov;64(3):224-30.

3. Ylipalosaari P, Ala-Kokko T, Laurila J, Ohtonen P, Syrjälä H. Epidemiology of intensive care unit (ICU)-acquired infections in a 14-month prospective cohort study in a single mixed Scandinavian university hospital ICU. Acta Anaesthesiol Scand. 2006 Nov;50(10):1192-7.

4. Klompas M. Ventilator-associated pneumonia: is zero possible? Clin Infect Dis. 2010 Nov;51(10):1123-6.

5. Chen Y-Y, Wang F-D, Chou P. Incidence rate and variable cost of nosocomial infections in different types of intensive care units. Infect Control Hosp Epidemiol. 2009 Jan;30(1):39-46.

6. Karhu J, Ala-Kokko TI, Ylipalosaari P, Ohtonen P, Laurila JJ, Syrjälä H. Hospital and long-term outcomes of ICU-treated severe community- and hospitalacquired, and ventilator-associated pneumonia patients. Acta Anaesthesiol Scand. 2011 Nov;55(10):1254-60.

7. Ricart M, Lorente C, Diaz E, Kollef M, Rello J. Nursing adherence with evidence-based guidelines for preventing ventilator-associated pneumonia. Crit Care Med. 2003 Nov;31(11):2693-6.

8. Kaynar AM, Mathew JJ, Hudlin MM, Gingras DJ, Ritz RH, Jackson MR, et al. Attitudes of respiratory therapists and nurses about measures to prevent ventilator-associated pneumonia: a multicenter, cross-sectional survey study. Respir Care. 2007 Dec;52(12):1687-94.

9. Gurses AP, Seidl KL, Vaidya V, Bochicchio G, Harris AD, Hebden J, et al. Systems ambiguity and guideline compliance: a qualitative study of how intensive care units follow evidence-based guidelines to reduce healthcare-associated infections. Qual Saf Health Care. 2008 Oct;17(5):351-9.

10. Pogorzelska M, Larson E. Assessment of attitudes of intensive care unit staff toward clinical practice guidelines. Dimens Crit Care Nurs. 2008 JanFeb;27(1):30-8.

11. Berhe M, Edmond M, Bearman G. Practices and an assessment of health care workers' perceptions of compliance with infection control knowledge of nosocomial infections. Am J Infect Control. 2005 Feb;33(1):55-7.

12. Jansson M, Ala-Kokko T, Ylipalosaari $P$, Syrjälä H, Kyngäs H. Critical care nurses' knowledge of, adherence to and barriers toward evidence-based guidelines for the prevention of ventilator-associated pneumonia - a survey study. Intensive Crit Care Nurs. 2013 Aug;29(4):216-27.

13. Blot SI, Labeau S, Vandijck D, Van Aken P, Claes B; Executive Board of the Flemish Society for Critical Care Nurses. Evidence-based guidelines for the prevention of ventilator-associated pneumonia: results of a knowledge test among intensive care nurses. Intensive Care Med. 2007 Aug;33(8):1463-7.

14. Labeau S, Vandijck D, Rello J, Adam S, Rosa A, Wenisch C, et al; EVIDENCE study investigators. Evidence-based guidelines for the prevention of ventilator-associated pneumonia: results of a knowledge test among European intensive care nurses. J Hosp Infect. 2008 Oct;70(2):180-5.

15. El-Khatib M, Zeineldine S, Ayoub C, Husari A, Bou-Khalil P. Critical care clinicians' knowledge of evidence-based guidelines for preventing ventilator-associated pneumonia. Am J Crit Care. 2010 May;19(3):272-6.

16. Blackwood B, Albarran JW, Latour JM. Research priorities of adult intensive care nurses in 20 European countries: a

\section{Licensee OA Publishing London 2013. Creative Commons Attribution Licence (CC-BY)}


Delphi study. J Adv Nurs. 2011 Mar;67(3): 550-62.

17. Institute for Healthcare Improvement: Implement the IHI Ventilator Bundle; 2011 [updated 14 Nov 2012; cited 02 May 2013]. Available at: http://www.ihi. org/knowledge/Pages/Changes/Implement theVentilatorBundle.aspx.

18. Tablan OC, Anderson LJ, Besser R, Bridges C, Hajjeh R; CDC; Healthcare Infection Control Practices Advisory Committee. Guidelines for preventing health-care-associated pneumonia. Recommendations of CDC and the Healthcare Infection Control Practices Advisory Committee. MMWR Recomm Rep. 2004 Mar;53(RR-3):1-36.

19. Rello J, Lode H, Cornaglia G, Masterton R; VAP Care Bundle Contributors. A European care bundle for prevention of ventilator-associated pneumonia. Intensive Care Med. 2010 May;36(5):773-80.

20. Cocoanour CS, Peninger M, Domonoske BD, Tao L, Wright B, Valdivia A, et al. Decreasing ventilator-associated pneumonia in a trauma ICU. J Trauma. 2006 Jul;61(1):122-9; discussion 129-30.

21. Bird D, Zambuto A, O’Donnell C, Silva J, Korn C, Burke R, et al. Adherence to ventilator-associated pneumonia bundle and incidence of ventilator-associated pneu- monia in the surgical intensive care unit. Arch Surg. 2010 May;145(5):465-70.

22. Pogorzelska M, Stone PW, Furuya EY, Perencevich EN, Larson EL, Goldmann D, et al. Impact of the ventilator bundle on ventilator-associated pneumonia in intensive care unit. Int J Qual Health Care. 2011 Oct;23(5):538-44.

23. Systematic Reviews. CRD's guidance for undertaking reviews in health care. Centre for Reviews and Dissemination, University of York; 2009.

24. Joanna Briggs Institute Reviewers' Manual. 2011 ed. The Joanna Briggs Institute; 2011.

25. Joanna Briggs Institute Reviewers' Manual. 2011 ed. Critical appraisal checklist for cohort/case control appraisal. The Joanna Briggs Institute; 2011.p153.

26. Omrane R, Eid J, Perreault MM, Yazbeck H, Berbiche D, Gursahaney A, et al. Impact of a protocol for prevention of ventilator-associated pneumonia. Ann Pharmacother. 2007 Sep;41(9):1390-6.

27. Bloos F, Müller S, Harz A, Gugel M, Geil D, Egerland K, et al. Effects of staff training on the care of mechanically ventilated patients: a prospective cohort study. Br J Anaesth. 2009 Aug;103(2):232-7.

28. Hawe CS, Ellis KS, Cairns CJS, Longmate A. Reduction of ventilatorassociated pneumonia: active versus passive guideline implementation. Intensive Care Med. 2009 Jul;35(7):1180-6.

29. Morris AC, Hay AW, Swann DG, Everingham K, McCulloch C, McNulty J, et al. Reducing ventilator-associated pneumonia in intensive care: impact of implementing a care bundle. Crit Care Med. 2011 Oct;39(10):2218-24.

30. Abbot CA, Dremsa T, Stewart DW, Mark DD, Swift CC. Adoption of a ventilator-associated pneumonia clinical practice guideline. Worldviews Evid Based Nurs. 2006;3(4):139-52.

31. DePalo VA, McNicoll L, Cornell M, Rocha JM, Adams L, Pronovost PJ. The Rhode Island ICU collaborative: a model for reducing central line-associated bloodstream infection and ventilatorassociated pneumonia statewide. Qual Saf Health Care. 2010 Dec;19(6):555-61. 32. Polit D, Beck C. Nursing Research. Generating and assessing evidence for nursing practice, 8th ed. Philadelphia: Lippincott Williams \& Wilkins; 2008. p244-56.

33. Burns N, Grove B. The practice of nursing research: appraisal, synthesis, and generation of evidence, 6 th ed. United States of America: Saunders Elsevier; 2009.p224-235. 